THIS IS AN EARLIER VERSION OF THE MANUSCRIPT. FOR THE FINAL VERSION, PLEASE CHECK THE JOURNAL WEBSITE: Serrano, R.; Muñoz, C. (2007). Same hours, different time distribution: Any difference in EFL? System 35, 305321.

\title{
Same hours, different time distribution: any difference in EFL?
}

\begin{abstract}
The effects of the distribution of instructional time on the acquisition of a second or foreign language are still not well known. This paper will analyze the performance of adult students enrolled in three different types of EFL programs in which the distribution of time varies. The first one, called 'extensive', distributes a total of 110 hours in seven months (the students receive four hours of instruction per week during the school year, starting in October and finishing in May). The second program is the 'semi-intensive', which offers the same number of hours distributed in three to four months, where the students receive instruction from eight to ten hours per week (depending on the semester where this course is implemented). Finally, the intensive course offers 110 hours in five weeks during the summer ( 25 hours of instruction per week). The results from our analyses suggest that concentrating the hours of English instruction in shorter periods of time is more beneficial for the students' learning than distributing them in many months.
\end{abstract}

Keywords: time distribution, English as a second language instruction, language learning, foreign language acquisition, intensive language courses, standard format courses.

\section{Introduction}

A consensus seems to exist that the more time available for learning the higher the proficiency levels attained, as demonstrated by research conducted prominently by the American psychologist J.B. Carroll four decades ago (Carroll, 1967). However, no similar consensus has been reached as to the way in which time for learning is to be distributed, and time allocations for language learning range from small amounts spread over a long period (the so-called 'drip-feed' distribution) to large amounts concentrated in a limited period. As Stern (1985:18) noted, very often a number of different considerations other than psychological or pedagogical have entered into decisions on the time for language learning (e.g., costs, urgency to achieve proficiency quickly, timetable convenience or limitations). As a case in point, the very well-known intensive language training programs that took place in the US during World War II were motivated more by the practical need to produce relatively high levels of proficiency rapidly than by a belief in the psychological advantages of massed over distributed learning. Since then intensive language learning, particularly for adults, has become a recognized pattern of language instruction, for example in language training for business and in universities. In contrast, the spread of languages to the first grades in primary schools which is taking place currently in many places entails small amounts of time stretched over several years.

This paper focuses on the effects of three different types of distribution of instructional time in EFL in a university setting, with the aim of finding empirical evidence concerning the benefits of allocating time in a massed or distributed manner. 
Because of the importance of psychological and pedagogical considerations in decision making concerning time (and timing) of foreign language learning, the paper starts by discussing a review of recent research in the field of cognitive psychology which has paid attention to the effects of time distribution on learning, and continues with a review of experience and research on the time factor in language pedagogy, before presenting the empirical study.

\subsection{Time distribution in cognitive psychology}

In the cognitive psychology literature study conditions in which repetitions of items to be learned appear in spaced or distributed sequences have been found to be more favorable for subsequent retrieval than presentations in which repetitions occur instantly (Braun and Rubin, 1998; Cuddy and Jacoby, 1982; Dempster, 1987; Greene, 1989; Hintzman, 1974; 1976; Melton, 1970; Russo et al. 2002; Seabrook et al. 2005; Toppino and Bloom 2002). This phenomenon has been called the spacing effect, according to which memory for items which are presented and then immediately repeated (massed practice) is worse than for items which are repeated after some intervening items have appeared (distributed practice).

Although the spacing effect is found constantly in most research contexts within the psychological literature, there is not much agreement as to why immediate repetitions of an item are not as effectively recalled as spaced repetitions. Several theories have been proposed, most of them falling into two main groups: encoding variability theories or deficient-processing theories.

Encoding variability theories emphasize the fact that spaced items are better recalled than massed because each presentation of the former is encoded differently, thus, providing more retrieval cues. The storage of new semantic or contextual information in the case of spaced items facilitates subsequent retrieval (Glenberg, 1979; Landauer, 1976; Melton, 1970). Deficient processing theories (Hintzman, 1976; Jacoby, 1978), on the other hand, claim that the second repetition of massed items does not receive enough processing because the previous presentation is still too recent. In contrast, when an item is presented after some time has elapsed and after some intervening items have been shown, full processing will be necessary, as the previous presentation will not be as readily available as in the case of massed presentations (Cuddy and Jacoby, 1982; Challis, 1993; Jacoby, 1978).

More recent accounts of the spacing effect also include study-phase retrieval theories, according to which retrieval of the first presentation when the second one occurs is essential for better recall (Braun and Rubin, 1998; Russo et al. 2002; Thios and D'Agostino, 1976; Toppino and Bloom, 2002; Toppino et al., 2002). According to Thios and D'Agostino (1976), an important role of the second presentation is to serve as cue to activate retrieval of old information. These researchers observed in their experiments that when the subjects were asked to retrieve the first presentation at the time of the second, a spacing effect took place in subsequent free-recall tasks. However, when subjects were simply given the second presentation, without them needing to retrieve the first one, no significant spacing effect was obtained.

As it can be seen, there is not one single explanation for why spaced repetitions are better recalled than massed repetitions, despite the fact that spacing effects are usually found. Russo et al. (2002) claim that a multifactor approach is necessary in order to explain spacing effects in explicit memory tasks. Similarly, Verkoeijen et al. (2004) explain the spacing effect in free-recall tasks through a model that combines contextual variability with study-phase retrieval. 
Notwithstanding the fact that the spacing effect has been claimed to be one of the most reliable, robust and ubiquitous phenomena in cognitive psychology (Dempster, 1988:627) some studies have found that, depending on different variables, the spacing effect can diminish or even disappear. Donovan and Radosevich (1999) in their review and analysis of the previous literature on the spacing effect suggest that the higher the complexity of the task (they define four different levels of complexity depending on physical, mental requirements, and overall complexity) the lower the spacing effect. Moreover, the researchers observed that those studies with low methodological rigor were the ones which obtained higher spacing effects. Another variable at play is the intertrial interval, which affected the spacing effect in an unpredicted way: the lower the intervals between trials (and as a consequence the closer the conditions were to massed practice) the higher the spacing effects. This finding is contradictory taking into account that, if spaced items are better recalled than massed, then, trials separated by long intervals should be expected to produce higher spacing effects, yet this result was not obtained. Donovan and Radosevich (1999) conclude that even if in their analysis spaced practice appears to be superior to massed practice; such superiority is not as clear as some studies in the past claimed.

The spacing effect has not been usually applied to classroom learning. Dempster (1987) states that most studies on the spacing effect cannot be applied to school-related activities, since the tasks used in the experiments are far from being typical classroom activities. Nevertheless, Dempster $(1988 ; 1996)$ considers that the spacing effect has some potential for classroom learning. In fact, some researchers have recently tried to take the experiments in the psychological literature from the laboratory to the classroom.

Seabrook et al. (2005) conducted an experiment in a classroom setting, analyzing the effects of teaching literacy in 'clustered' sessions (which are claimed to be similar to massed) and distributed sessions. The children who followed distributed teaching lessons showed significantly more improvement than those following clustered sessions. From their analyses, the researchers conclude that results from laboratory experiments on the spacing effect can be applied to classroom settings in order to improve learning.

\subsection{Time distribution in second language teaching}

The results obtained in cognitive psychology experiments are not in line with findings reported in the language program evaluation literature. Traditional second/foreign language programs which provide limited hours of instruction per week in a non-concentrated time distribution have not been shown particularly effective in the acquisition of a second language (Netten and Germain, 2004; Spada and Lightbown, 1989). As a consequence, several new programs have been designed and implemented which provide enriched second language instruction. Among these programs, we could highlight all the different models which have developed in Canada, a country where second language education is an issue of major importance: immersion education, intensive English, and intensive French (Netten and Germain, 2004).

The first immersion class in the public sector began in 1965 in St. Lambert, a suburb in Montreal, mainly because of the concerns some parents had about their children's poor French language skills after years of French instruction (Lambert and Tucker, 1972). In a few years, immersion classes were held in other areas in Canada, mainly in the provinces of Quebec and Ontario. Three different types of French immersion programs were designed: early total immersion (which was the first model), 
early partial immersion and late immersion (Swain, 1985). Evaluations from different researchers promptly showed that immersion children were able to acquire high levels of competence in French without it having any negative repercussion on the students' cognitive development, English skills or content knowledge for the subjects that were implemented in French (Barik and Swain, 1974; Lambert and Tucker, 1972; Swain and Barik, 1976).

Intensive English programs started in Quebec due to similar types of concerns about the children's second language competence, although this time those concerns were coming from the French-speaking community, which was not highly satisfied with the francophone students' command of the English language. These innovative programs were also spurred by the fact that immersion in English is not allowed in French schools. In intensive English programs the students are in contact with the language for several hours per day; however, they do not receive content instruction in this language. The focus in this program is on the English language itself (since language laws in Quebec do not allow the provision of content instruction in English in French-medium schools), and more specifically on oral fluency. There is an increased amount of hours in intensive English programs with respect to the traditional 'drip-feed' programs. The former is normally offered in grade 6 (when the students are 11-12 years of age), sometimes in grade 5, and provides students with approximately 400 hours of ESL instruction in that year.

This type of intensive program stands in contrast to the regular program, in which the majority of school age Canadians still receive their instruction, which in Quebec is typically 1 or 2 hours a week in elementary school, starting now in grade 1 (as opposed to grade 3 which was the typical starting age until 2006) with a total of 3570 hours per year, depending on the school. In secondary school there is an average of 2.5 hours per week of English instruction from grades 7-11.

Results from research studies seem to indicate that those students enrolled in intensive English programs outperform their partners from the same grade who receive traditional English instruction (White and Turner, 2005). Moreover, students in intensive programs surpass their partners with similar amount of hours of instruction at higher grades (Lightbown and Spada, 1994; Spada and Lightbown, 1989).

As happened with immersion programs, there have been different models of implementation of intensive English, depending on the distribution of instruction time across the school year (Collins et al., 1999). First of all, there is the 'massed program', where students receive 350-400 hours of English instruction in five months. There is also the 'massed plus program', where students are in addition encouraged to use English outside the class (in the hallways, cafeteria, etc.) Then, there is the distributed program' where 300-350 hours are spread across the school year (10 months). Collins et al. (1999) report that students who received massed instruction outperformed those who were enrolled in a distributed program. This finding seems to suggest that one feature that may be important with respect to intensive English programs is the fact that exposure to English is not only longer (more hours of instruction) but also more concentrated than in traditional ESL programs. The authors caption, however, that the findings are inconclusive because the massed groups ended up having more hours than the distributed group, and the differences are relative since the three groups made considerable progress.

Even if the intensive English program in Quebec has been quite successful and has had some continuity since its beginning, intensive French did not experience a similar success at first, probably due to the great popularity of French immersion education. The situation is changing at present and intensive French programs are 
gaining increasing support (Netten and Germain, 2006). Although different programs were experimented in different parts of Canada since 1975, none was widely accepted and extended. Le bain linguistique in the Ottawa School Board during the years 19931996 and later on in 1999-2000, and the block scheduling in the Carleton Board of Education in 1993-1994 stand among the best documented programs (see Netten and Germain, 2004).

Le bain linguistique followed the principles of intensive English, adopting the 'distributed model', that is, offering approximately 450 hours of French instruction in one year, as opposed to the 120 hours offered in the traditional, or core French program. Results from different research projects show that the students who were enrolled in this intensive program progressed more in their French skills than those students in regular French classes; furthermore, those students in le bain linguistique program showed more self-confidence in French and also more positive attitudes towards the learning of this language (MacFarlane, Peters and Wesche, 2004; Peters, 2000).

Another attempt at enriching core French was the block-scheduling undertaken by the Carleton Board of Education. Contrarily to intensive English and le bain linguistique, this model does not increase the amount of hours devoted to the second language with respect to the traditional core French model; rather, it distributes the same amount of hours differently. Two models of block scheduling were proposed: one in which the students had half days of instruction in French over a 10 week period (the half-day model), and another one which offered 80 minutes of French a day over 5 months. Compared to core French, which provides 40 minutes of instruction a day over the whole school year, the other two models were more intensive in the sense that instruction was more concentrated than in the traditional model. Lapkin, Hart and Harley (1998) show that the students in half-day classes outperformed the students in the regular French program, especially in reading and writing. Those students in the 80minute program were also superior to the students in the traditional model; however, the differences in performance between the two groups were not statistically significant.

All the studies that have analyzed the different intensive language programs in Canada show positive results for those models that concentrate and/or enrich second language instruction. Most of the research previously mentioned has been taken place in elementary or secondary schools; however, there has also been some research for adult learners, even though such research is not as abundant (Mckee, 1983). In a study which compared the progress made in French by university students in intensive language courses, traditional classes and study-abroad stays in France, those students in the intensive 'at home' context were reported to be the most successful in the acquisition of certain aspects of fluency in French (Freed, Segalowitz and Dewey, 2004). At the same time, intensive learners claimed to use more French outside the class (in extracurricular activities which were arranged for them) than students in the other two contexts. Additionally, some studies have shown that concentrated language courses are beneficial for the students because they increase group cohesion in the class as well as students' motivation (Hinger, 2006). Table 1 provides a summary of the main studies that have investigated time distribution in language learning.

These data from the language program evaluation literature stands in contrast with the results from the experiments in cognitive psychology, since more concentrated exposure seems to bring about more learning than more spaced lessons. These findings may suggest that the process of learning a language is highly different from the process of memorizing random lists of words, for which having distributed presentations seemed to be more effective than concentrated or massed exposure (as reported in the cognitive psychology literature). 


\subsection{Research question and hypothesis}

The question which guides our research is the following: is it possible to find differences in the acquisition of English as a foreign language by students who are enrolled in different types of programs (extensive, semi-intensive and intensive) where the distribution of instruction hours varies? In contrast to most of the reviewed cases, the situation studied here keeps the number of hours constant, so that only time distribution changes for each language program were considered. A strength of this study is also the control of a number of variables, both internal to the participants such as age (young adults) and education (tertiary level), as well as contextual, such as textbooks and teaching materials, teaching methodology, and curriculum.

Taking into account previous research on the effectiveness of concentrating the hours of instruction of a second language (Collins et al., 1999; Lapkin, Hart and Harley, 1998; Netten and Germain, 2004, Peters, 2000; Spada and Lightbown, 1989), we should expect to find differences in favor of semi-intensive and intensive programs with respect to extensive programs.

\section{Method}

\subsection{Programs and Participants}

Three different programs were chosen for this study: extensive, semi-intensive and intensive ${ }^{1}$. These programs were offered in the same institution, which is the language school of the University of Barcelona. In all the three models English is taught for 110 hours; however, those hours are distributed in a different way. The extensive program starts in October (which is the beginning of the academic year) and it offers four hours per week of English instruction distributed in two days (MondaysWednesdays or Tuesdays-Thursdays). These classes continue until the end of the school year in May, over a total of seven months. Semi-intensive courses are offered twice over a school year: during the first semester from October until December, and during the second semester from February until May. Students enrolled in the former receive ten hours of instruction per week (two and a half hours per day Monday through Thursday) over a total of eleven weeks. Students attending the semi-intensive course the second semester receive eight hours of instruction per week (two hours a day Monday through Thursday) during approximately fifteen weeks. Finally, the intensive program offers five hours a day of English instruction from Monday through Friday during a period of nearly five weeks from the end of June until the end of July.

A total of 114 students distributed in six different groups (two groups per program) were enrolled in the classes under research. Of these, 76 were present for all testing sessions: 22 from the extensive program, 33 from the semi-intensive program and 21 from the intensive program.

All the students in the different programs had similar characteristics: they all attended level 3 (intermediate) classes; moreover, they were mainly university students (ages 18 to 24) who were studying different degrees and were taking English as an elective. Although each group had a different teacher, (unfortunately it is impossible to neutralize this variable in this study) all the instructors used the same textbook and

\footnotetext{
${ }^{1}$ The data presented here forms part of a larger research project which includes students with different levels of English proficiency in intensive, semi-intensive and extensive programs, as well as a wider sample of students included in the level considered for this particular study.
} 
followed a similar methodology. At the beginning of each unit there were reading and listening activities which served as an introduction to the specific grammar points and vocabulary items which were to be learned. Additionally, the students had the opportunity to practice their oral skills through different speaking activities related to the topic presented in each unit.

\subsection{Procedure}

The same data collection procedure was followed for the three different types of programs. First of all, the students took a test at the beginning of the course (approximately 20 hours after the classes had started). It was not possible to test the students earlier, since there are usually changes at the beginning of each course and the coordinator recommended that we started with the data collection once the classes were more or less settled. Then, the same test was repeated at the end of the course, more or less after 85 hours of instruction, 65 hours after the pretest. The students spent approximately one hour to complete both the pre and the posttest, which was taken during class time, either at the beginning or at the end of the class, without the students knowing in advance that they would be tested.

\subsection{Measures and analyses}

In order to analyze the students' progress in English several tasks were used which aimed at addressing the four different language skills: listening, reading, speaking and writing. The written test which all the students took was a short version of the practice exam used in the language school under research (with the same format as the final exam). Only a few exercises were chosen, due to the fact that our intention was for the test to last no more than one hour. The reasons why such test was chosen were mainly practical. First of all, the test gives the students a chance to prepare for the final exam; consequently, their participation in our project was expected to be more enthusiastic. Moreover, since the activities in the test had been used as practice exam before, they were thought to be appropriate to test the contents taught in the level under research. The activities included in the test were a listening comprehension exercise, a sentence conversion exercise, an open cloze activity, a reading activity and a composition (150 words approximately) ${ }^{2}$.

This paper will only focus on the findings from the first four tasks included in the practice exam test. The exercises used in order to assess listening, grammar, vocabulary and reading performance were analyzed in terms of accuracy to provide the correct answer in each case. In most cases there was only one alternative, but in the more problematic exercises, as the sentence conversion, half marks were given when the student provided an answer which was almost correct.

For the listening comprehension, the students had to listen to a radio newsreader giving information about a competition. The students listened to this information twice

\footnotetext{
${ }^{2}$ Apart from those activities, a subset of students in each group was randomly chosen to do some
} speaking activities, which included a personal interview, a picture description and a role play. The students completed the first two tasks individually and did the role play in pairs. The analysis of the oral data, as well as the analysis of the compositions, is still in progress. 
and had to read several sentences related to the information presented, completing six blanks (worth one point each) with words the speaker used.

The sentence conversion exercise included five sentences (worth one point each) which the students had to paraphrase. The students were given the first words in the sentences. Several grammar points were tested in this activity: use of the passive, use of enough, linkers, modal verbs for requests and conditionals.

After this exercise, the cloze activity with the title 'A long journey' also tested some grammar and vocabulary points: use of never/ever, all/everything, another/other, relative pronouns, verb tenses, modal verbs, much/many, and conjunctions. All these grammar points were a central part of the level 3 syllabus. The activity included 10 gaps, which required the use of one appropriate word each, and the students could obtain a maximum of five points (half a point for each correct response).

With respect to the reading, the students were given a text called 'British Seaside Resorts', which presented information on five tourist locations in Britain. After reading the text, in Section A, the students had to decide which resort they would recommend to people who liked doing different activities: amusement parks, scenery, etc. Here the students had 10 items to complete and were given a maximum of 5 points. Section B provided five words for which the students had to find synonyms in the paragraphs indicated within the text. The maximum number of points in this section was also 5 .

\section{Findings}

Students in all the three programs improved from the beginning until the end of the course. The following table shows the means and standard deviations (in parentheses) for each task with respect to program type.

Insert Table 2 here

Four two-way mixed ANOVAs were performed, one for each test: listening, sentence conversion, cloze and reading tests. A significant main effect for time was found in the four analyses (see Table 3 for the respective values).

Insert Table 3 here

None of the ANOVAs yielded a significant main effect for program and nor was a significant interaction effect found for program by time (only very marginally significant in the case of the listening test; see Table 3). An investigation of the simple main effects showed that there were no differences between the three groups neither in the pretest nor in the posttest in any of the four language measures. Pairwise comparisons were run, applying the Bonferroni adjustment for multiple comparison. Contrasts revealed that both the semi-intensive group and the intensive group made significant progress from pretest to posttest in the listening test, the sentence conversion test, the cloze test and the reading test (see Table 3 ). In contrast, the extensive group made only modest gains that were not statistically significant in three of the four tests: listening, sentence conversion and reading test; gains were significant in the cloze test but the means difference for the extensive group was the smallest of the three groups, followed, in this order, by the intensive group, and the semi-intensive group (see Table 3 ). These results are illustrated in the following figures (figures 1-4), which represent the progress made by each of the groups in each of the tasks from the pretest to the posttest. 
Insert Figure 1 here

Insert Figure 3 here
Insert Figure 2 here

Insert Figure 4 here

In sum, although no significant interaction effects that related improvement to intensity were found, a clear distinction was revealed between the three types of program in terms of the progress learners made between the pretest and the postest. Scores on the listening test, the sentence conversion test and the reading test significantly improved for learners in the semi-intensive and the intensive groups, but not for learners in the extensive group. On the other hand, while scores on the cloze test improved for learners in all the groups, the extensive group had the lowest means difference between the pretest and the posttest, and the smallest partial eta squared value. Differences between the values obtained for the semi-intensive and the intensive groups were not large, although the partial eta squared values were slightly larger for the intensive than for the semi-intensive group in all the measures, with the exception of the cloze test.

\section{Discussion and Conclusion}

Our results show that those students registered in extensive classes make less progress in a 110-hour course than those in intensive groups (both semi-intensive and intensive, since in both type of programs students obtained similar results). The students in the extensive program obtained lower scores than those registered in the other two groups in the posttest, although differences do not reach significance level (which could be due to the small number of subjects in each type of program). Furthermore, while students in semi-intensive and intensive programs significantly improve their results in the four tasks considered, from the beginning until the end of the course, students in the extensive program improve their results during that period only in the cloze task.

Although our findings are still preliminary, they seem to suggest that concentrating second language instruction has a positive impact on the students' acquisition of certain aspects of a particular language, as other studies have previously shown (Collins et al. 1999; Lightbown and Spada, 1994; Peters, 2000; Spada and Lightbown, 1989, White and Turner, 2005). The claim that intensive programs are more effective than extensive programs may indicate that, contrarily to what some cognitive psychology research studies have shown (Dempster, 1987; Glanzer and Duarte, 1971; Hintzman, Block and Summers, 1973; Melton, 1970; Seabrook et al. 2005), massed practice can be more effective than distributed practice with respect to language learning.

To conclude, the present study has analyzed the progress made at the end of their respective course by students in different types of foreign language learning programs which differ in terms of time distribution. The main findings from our analyses suggest that concentrating the hours of foreign language instruction seems to be more beneficial for the students than distributing them across time. Even though the hours of instruction are the same in the different language programs which have been considered for this study, those students in intensive and semi-intensive programs made a significant progress in all the language areas under study as opposed to those students in extensive programs, which made some progress at the end of the course, yet their progress was not as significant. Such finding, together with similar results from Canadian research, may be highly useful for language planners when they make decisions as to how much 
time should be devoted to foreign language instruction, as well as in which way such time should be distributed.

Further research should include delayed posttests in order to observe how much knowledge is retained after some time has passed, in order to make stronger claims about how time distribution affects the acquisition of a foreign language. In future studies we will also include different levels of proficiency in the three different types of programs presented in this paper, as well as a higher number of students, and results from oral tasks. We will then be able to observe the ways in which intensity of instruction may be related to level of proficiency and to different language skills.

\section{Acknowledgments}

We would like to thank L. Collins and J. White for their updated information about English language teaching programs in Quebec. We also thank L. Collins for her very helpful comments on an earlier draft of this paper.

\section{References}

Barik, H.C., Swain, M., 1974. English-French bilingual education in the early grades: The Elgin Study. Modern Language Journal 58, 392-403.

Bloom, K.C., Shuell, T.J., 1981. Effects of massed and distributed practice on the learning and retention of second-language vocabulary. Journal of Educational Research 74, 245-248.

Braun, K., Rubin, D.C., 1998. The spacing effect depends on an encoding deficit, retrieval and time in working memory: evidence from once-presented words. Memory 6 (1) 37-65.

Carroll, J.B., 1967. Foreign language proficiency levels attained by language majors near graduation from college. Foreign Language Annals 1, 131-151.

Challis, B.H., 1993. Spacing effects on cued-memory tests depend on level of processing. Journal of Experimental Psychology, Learning, Memory, and Cognition 19 (2), 389-396.

Collins, L. et. al., 1999. Time and the distribution of time in L2 instruction. TESOL Quarterly 33 (4), 655-680.

Cuddy, L.J., Jacoby, L.L., 1982. When forgetting helps memory: an analysis of

Dempster, F.N., 1987. Effects of variable encoding and spaced presentations on vocabulary learning. Journal of Educational Psychology 79 (2), 162-170.

Dempster, F.N., 1988. The spacing effect: a case study in the failure to apply the results of psychological research. American Psychologist 43, 627-634.

Dempster, F.N., 1996. Distributing and managing the conditions of encoding practice. In: Bjork E.L., Bjork, R.A. (Eds.), Memory. Academic Press, London, pp. 318339.

Donovan, J.J., Radosevich, D.J., 1999. A meta-analytic review of the distribution of practice effect: now you see it, now you don't. Journal of Applied Psychology 84 (5), 795-805.

Glanzer, M., Duarte, A., 1971. Repetition between and within language in free recall. Journal of Verbal Learning and Verbal Behavior 10, 625-630.

Glenberg, A., 1979. Component-levels theory of the effects of spacing. Memory and Cognition 7, 95-112.

Greene, R.L., 1989. Spacing effects in memory: Evidence for a Two-Process Account. Journal of Experimental Psychology, Memory and Cognition 15 (3), 371-377. 
Hintzman, D.L., 1976. Repetition and memory. In: Bower, G.H. (Ed.), The Psychology of Learning and Memory. Academic Press, New York, pp. 47-91.

Hintzman, D.L., Block, R.A., Summers, J.J., 1973. Modality tags and memory for repetitions: locus of the spacing effect. Journal of Verbal Learning and Verbal Behavior 12, 229-238.

Hinger, B. 2006. The distribution of instructional time and its effect on group cohesion in the foreign language classroom: a comparison of intensive and standard format courses. System 34, 97-118.

Hintzman D.L. et al., 1975. Spacing judgments as an index of study-phase retrieval. Journal of Experimental Psychology: Human Learning and Memory 1, 31-40.

Jacoby, L.L., 1978. On interpreting the effects of repetition: Solving a problem versus remembering a solution. Journal of Verbal Learning and Verbal Behavior 17, 649-667.

Lambert, W.E., Tucker, G.R., 1972. Bilingual Education of Children. Newbury Publishers Inc, Rowley, MA.

Landauer, T.K., 1969. Reinforcement as consolidation. Psychological Review 76 (1), 82-96.

Lapkin, S., Hart, D., Harley, B., 1998. Case study of compact core French models: Attitudes and achievement. In: Lapkin, S. (Ed.), French Second Language Education in Canada: Empirical Studies. University of Toronto Press, Toronto, ON, pp. 3-31.

Lightbown P.M., Spada, N., 1994. An innovative program for primary ESL students in Quebec. TESOL Quarterly 28 (3), 563-579.

MacFarlane, A., Peters, M., Wesche, M., 2004. Le bain linguistique: Programme intensif de français langue seconde à Ottawa. Canadian Modern Language Review 60 (3), 373-391.

Melton, A.W., 1970. The situation with respect to the spacing of repetitions and memory. Journal of Verbal Learning and Verbal Behavior 9, 596-606.

Mckee, E. 1983. The effects of intensive language instruction on student performance in beginning college French. Paper presented at the Central States Conference on the Teaching of Foreign Languages (St. Louis, MO, March 24-26, 1983).

Netten, J., Germain, C., 2004. Theoretical and research foundations of Intensive French. Canadian Modern Language Review 60 (3), 275-294.

Netten, J., Germain, C., 2006. A pedagogical perspective on second language acquisition. Joint AAAL and ACLA/CAAL Conference. June 17-20, Montreal.

Peters, M., 2000. Le bain linguistique: une innovation pour le programme de français de base. Apprentissage et Socialisation 20 (2), 71-86.

Russo, N. et al., 2002. Toward a unified account of spacing effects in explicit cuedmemory tasks. Journal of Experimental Psychology, Learning, Memory, and Cognition 28 (5), 819-829.

Seabrook, R. et al., 2005. Distributed and massed practice: from laboratory to classroom. Applied Cognitive Psychology 19, 107-122.

Segalowitz, N., Freed, B. F. 2004. Context, contact, and cognition in oral fluency acquisition. SSLA 26, 173-199.

Spada, N., Lightbown, P.M., 1989. Intensive ESL programmes in Quebec primary schools. TESL Canada Journal 7 (1), 11-32.

Stern, H.H., 1985. The Time Factor and Compact Course Development. TESL Canada Journal/Revue TESL du Canada 3 (1), 13-27

Swain, M., Barik, H.C., 1976. Five Years of French Immersion. Toronto, Ontario, The Ontario Institute for Studies in Education. 
Thios S.J., D'Agostino, P.R., 1976. Effects of repetition as a function of study-phase retrieval. Journal of Verbal Learning and Verbal Behavior 15, 529-536.

Toppino, T.C., 1991. The spacing effect in young children's free recall: support for automatic process explanations. Memory and Cognition 19, 159-167.

Toppino, T.C., DiGeorge, W., 1984. The spacing effect in free recall emerges with development. Memory and Cognition 12 (2), 118-122.

Verkoeijen P.P.L. et al., 2004. Detrimental influence of contextual change on spacing effects in free recall. Journal of Experimental Psychology: Learning, Memory and Cognition 30 (4), 796-800.

White, J., Turner, C. E. 2005. Comparing children's oral ability in two ESL programs. Canadian Modern Language Review, 61 (4), 491-517.

\section{Figure captions}

Figure 1: Progress in the listening task from pretest to posttest by the three groups

Figure 2: Progress in the sentence conversion task from pretest to posttest by the three groups

Figure 3: Progress in the cloze task from pretest to posttest by the three groups

Figure 4: Progress in the reading task from pretest to posttest by the three groups

\section{Tables}

Table 1: Scores and Standard Deviations

Table 2: Results of the statistical analyses 